\title{
Energy Challenge, Power Electronics \& Systems (PEAS) Technology and Grid Modernization
}

\author{
Don Tan and Damir Novosel
}

\begin{abstract}
Modern society has reached a point where virtually every crucial economic and social function depends on the secure and reliable operation of the electrical power and energy infrastructures. The energy consumption growth and the population growth are pushing world's total energy consumption to double by 2050 . This represents grand challenges and opportunities for power electronics and electric power systems engineers to modernize the power grid. Power electronics \& systems (PEAS) technology is increasingly important for smarter distributed systems, particularly for power grid modernization. This paper discussed smart technology solutions, such as PEAS, for the changing nature of the electric power system. Specific technical challenges that are facing the power electronics and electric power systems communities are then elaborated. It is shown that we can meet the grand energy challenge by leveraging the grid modernization efforts. To provide electric power to twice as many people does not have to increase the required environment footprint.
\end{abstract}

Index Terms-Power electronics, electric power systems, grid modernization, energy challenges, energy solutions, large electronic power transformers, renewable energy, all things grid connected.

\section{INTRODUCTION}

$\mathrm{T}$ HE electrical grid is an amazing engineering achievement. The US National Academy of Engineering named it as number one among the top twenty engineering achievements for its "vast networks of electricity to provide power for the developed world" [1]. Over the last century, the grid has evolved into a system of systems. The technology is mature and electricity reliability (availability) is $99.99 \%$ or better. However, the basic technology of the electrical power grid was developed about a century ago and has been incrementally improved and its operation evolved [2], as new technologies, such as computing, sensors, and communications networking, became available. The electric power systems in the industrialized world, in addition to generally being quite old, particularly in large metropolitan areas, face challenges caused by new technology deployment trends, environmental concerns, new weather patterns, changing consumer needs, and regulatory requirements. New technology trends include development of more efficient, reliable, and cost-effective renewable generation and Distributed

Manuscript received March 10, 2017.

Don Tan is with Northrop Grumman Aerospace Systems (NGAS), Redondo Beach, CA, USA, Damir Novosel is with Quanta Technology and Energized Services (e-mail: don.tan.oc@gmail.com).

Digital Object Identifier 10.24295/CPSSTPEA.2017.00002
Energy Resources (DER), energy storage technologies, Electric Vehicles (EV), monitoring, protection, automation, and control devices, and communications that offer significant opportunities for realizing a sustainable energy future.

In the past, the distribution system was designed and built to serve peak demand (and comply with reliability and quality of service requirements) and was a passive delivery infrastructure with a radial "down and out" paradigm for the delivery of energy to consumers. Consumers used what they needed/wanted, the wholesale infrastructure provided the energy, and the T\&D system delivered it with no need for real-time operation of the distribution system. Distribution operations consisted of construction, maintenance, and outage management - not of managing delivery per se. Today, customers are increasingly using the grid as a means to balance their own generation and demand and also as a supplier of last resource when their generation is unavailable. They expect to deliver excess generation back to the grid and to be paid for it, without restrictions on their production. And they still expect the grid to "be there" when they need it. In order to meet these needs, the very architecture of the distribution grid has to change and adopt new technologies, ways of planning, and ways of operating. Consumers are demanding changed business models and regulators and policy makers are striving to satisfy and even encourage them, sometimes running ahead of the grid's abilities to accommodate the new policies.

With the proliferation of smart devices, such as smart phones and other emerging wearable smart devices, a wave of industry systems are being digitized with computing power to be smart. It is safe to predict that all things that were industrialized will be digitized in order to make it smart. The future of our society will be revolutionized by the distributed smarter systems [3].

The grid that was originally developed in the last century requires addressing following issues due to integration of distributed energy resources (DER): 1) Bidirectional power flow; 2) Low fault currents and inadequate fault isolation; 3) Improved voltage management; 4) Low system inertia requiring improved frequency regulation; 5) Maintaining or improving reliability 6) Maintaining or improving safety 7) Transmission congestion; and 8) Efficient system operation and maintenance.

Power electronics \& systems (PEAS) technology plays increasingly discriminatory role in grid modernization, electric vehicles, self-driving cars, and industrial drives, to name a few. Grid modernization represents a particular area where a significant growth has been happening in the utility indus- 
try with many power electronics and electric power system related projects and technology development centers. However, a systematic understanding of issues and potential challenges and opportunities has not been fully explored. This paper is an attempt to address the missing pieces.

This paper is further organized as follows. Section II describes a grand challenge that is facing our society for the near future. Section III discusses the grid resilience and breadth and severity of the challenges related to aging power grid, physical and cyber security, and weather related issues. Section IV explains technologies to address the changing nature of the electric power system. Section V presents the grid challenges and opportunities the power electronics and electric power systems community face. Section VI points out that grid modernization will lay down a solid foundation for safe and reliable electrical energy delivery. Section VII summarizes recent development trends for PEAS technology. Section VIII describes the future options and recommendations to address grid transformation and possible solutions for meeting the grand energy challenge without having to increase the environmental foot print. And finally conclusions and references are presented at the end.

\section{A Grand Energy Challenge}

Refer to Fig. 1. According to a report released by the United Nations in 2000, the world's energy consumption will

GLOBAL PRIMARY ENERGY REQUIREMENT, 1850-1990, AND IN THREE CASES, 1990-2100

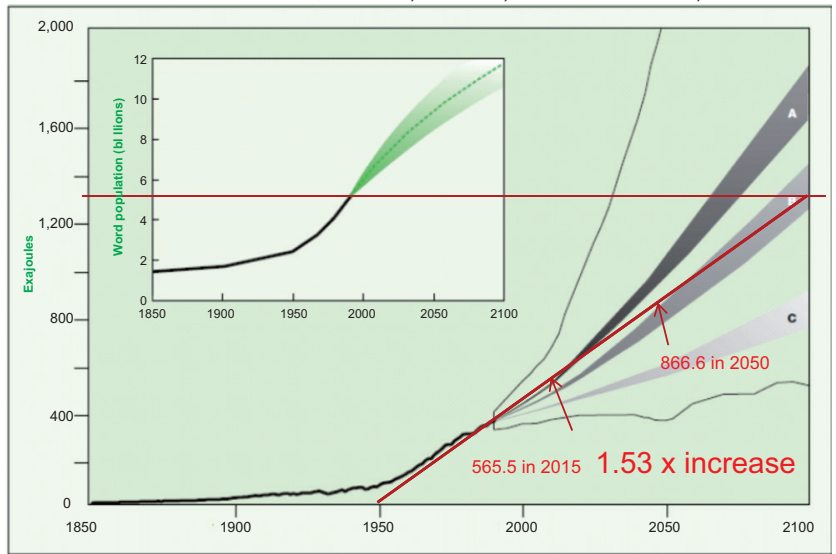

Fig. 1. World's energy consumption is projected to increase approximately by 1.53 times per year according to the United Nations.

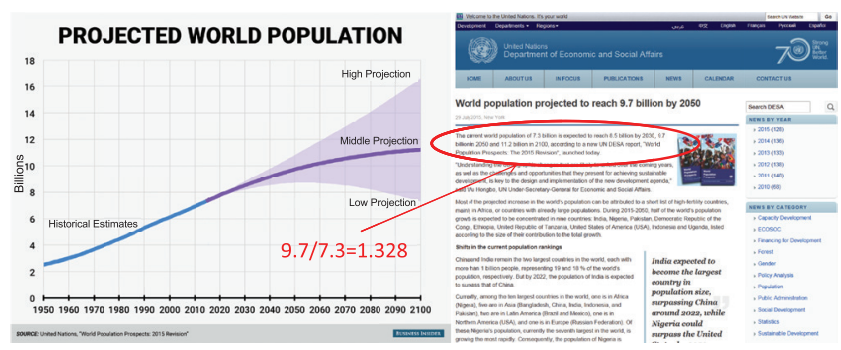

Fig. 2. World's population is projected to increase approximately by 1.328 times by the year of 2059 according to the United Nations. grow by $53 \%$ from 2015 to 2050 [4]. In the meantime, the United Nation, in a dual report, also projected that world's population will increase by $32.8 \%$ from 2015 to 2050 [5] (Fig. 2). So the composite growth for energy consumption is projected to double from 2015 to 2050 . The large increase of the energy consumption is expected to increase the energy environmental footprint significantly [6]. This represents a grand challenge for modern societies and their global citizens.

\section{GRID RESILIENCE}

While the electrical power system is becoming and will continue to become more distributed, it is important to note that today's interconnected grid began as a distributed grid. Interconnected grids were created to improve grid cost-efficiency, reliability, service quality, and safety. As technology advancements made it easier to deploy renewable resources and, controllable, more efficient distributed grids, the fundamental benefits of a connected grid still hold and in fact, become more important. While the present grid is generally considered reliable, as dependency on the digital economy grows, users will demand even more reliability from the electric power delivery in the future, including resilience during major weather or security events. Transmission and distribution systems are an enabler to deployment of renewable resources, providing pathways for the transport of clean energy between production and consumption centers and a means for resource movement and delivery, while at the same time fortifying electric system efficiency, stability and reliability of supply. Integration of DER and distributed grids can increase efficiencies in the use of the existing grid, as well as become part of the overall development strategy to balance the supply and demand uncertainties and risks with a variety of different resources [7]-[10]. In cases where distributed grids become predominant (e.g. renewable intermittent DER plus energy storage), and grid usage becomes equally as variable, assuring a safe and reliable supply will require an intelligent, modern, resilient, flexible and safe grid.

Recently, grid resiliency is attracting more attention as weather events are becoming increasingly more frequent and damaging and as security threats external to the grid are increasing [11]. Changing weather patterns are leading to increased frequency of severe events and associated risks for electric utilities, such as extreme temperatures accompanied by abnormal peak demands, severe droughts accompanied by wildfires and infrastructure damage, etc. Average temperature rise stresses grid equipment (e.g. transformers and $\mathrm{T} \& \mathrm{D}$ lines), including reducing its life-time. In addition to adapting planning and operations practices to this "new normal", the above effects require updated equipment design, as well as different engineering and construction practices to counteract the impact of climate change and enable the adoption of new technologies.

In the meantime, the power grid infrastructure is aging with an alarming scale and at an alarming rate, according to a recent US Department of Energy report [12]. For instance, 
large power transformers and much of power equipment are designed typically for 25 years' of life. But currently, a total of $70 \%$ of large transformers are 25 years or older, a total of $60 \%$ of circuit breakers are 30 years or older; and a total of $70 \%$ transmission lines are 25 years or older, to name a few.

More alarmingly, the impact of potential failure on the power grid is huge. A one-time loss of large power transformer can mean a temporary power outage for about 500,000 homes. A replacement of failed power transformer can take up to 2 years. A severe weather related event, such as Super Storm Sandy in the US, can inflict damage in the order of $\$ 28 \mathrm{~B}$ to $\$ 168 \mathrm{~B}[13]$.

Transmission lines are typically loaded to $50 \%$ in order to be able to deliver the peak power to the consumers during the peak usage time. Because of the environmental restrictions and costs associated with building new transmission lines, transmission system is often congested. Bottleneck is the weakest link in the transmission and is frequently the limiting factor for effective and efficient power flow. Congestion cost is estimated to be in the order of $\$ 1 \mathrm{~B}$ to $\$ 2 \mathrm{~B}$ in the last decade, according to a report from PJM based on data from its operations [14].

In summary, aging infrastructure should not be treated as an isolated concern; rather it should be viewed in the context of holistic asset management [15]. The entire equipment fleet must be managed to achieve system reliability and meet customer service needs through effective planning and operations. Holistic approach in support of business goals includes management of Aging Infrastructure (including condition monitoring and assessment tools), Grid Hardening (weather related response, physical vulnerability and cyber security), and System Capabilities (including reliability improvements). It also includes:

- Managing new Smart Grid assets such as advanced metering infrastructure and intelligent electronic devices.

- Investigate practical measures to shorten times to replace and commission equipment that failed due to extreme events, physical attacks, or other reasons.

- Better coordination of electricity and gas markets, including developing operational tools to more accurately forecast the availability of natural gas supply for generators and to improve unit commitment decisions.

\section{Smart Technologies for the Changing Nature of the Electric Power System}

To address the grand energy challenges in the coming century, the US Department of Energy (DoE) launched the smart grid initiative under the Energy Independence and Security Act in 2007. Since then, the smart grid today has evolved to include the application of advanced communications and control technologies and practices to improve reliability, efficiency, and security. Specific technical areas include the following [16].

- Advanced metering infrastructure is comprised of smart meters, communication networks, and informa- tion management systems. It also includes customer-based technologies, such as programmable communicating thermostats for residential customers and building energy management systems for commercial and industrial customers. The architecture includes integration of sensing, communications, and control technologies with field devices in distribution systems to improve reliability and efficiency.

- Advanced distribution and substation automation technologies include digital relays, substation automation computers and data concentrators, and gateways to Distribution Management Systems (DMS), and Energy Management Systems (EMS) systems - are fully commercial and proven technologies. They need to be implemented in large scale with full utilization of their key capabilities. Distribution and Substation Automation promise enhanced grid flexibility as well as improved asset management that will increase asset lives, reduce costs, and improve reliability. However, only around $50 \%$ of US distribution substations are fully automated today.

- Intelligent and adaptive reclosers and switches isolate faults in smaller sections to support increased flexibility and improve reliability with both traditional and distributed grids.

- Digital system protection is adaptive to system conditions will need to be widely used. Distributed Energy Resources (DERs) with inverter technology create various operating scenarios which are not presently addressed by existing protection schemes. Circuit power flows and fault current levels will change based on DER size, output, and location on the circuit.

- Advanced sensors and management systems are required to provide cost-effective monitoring of key electric variables, including bi-directional power flows, voltages, currents, equipment and DER status, etc., as well as fault information to circuit breakers and other protection devices. The ability to control DER on a five-minute basis will require overall bandwidth beyond the typical AMI network capacity. It will be essential to have enough real-time monitoring of circuit conditions to provide situational awareness and to support applications such as distribution state estimation. Faster more intelligent and flexible volt-VAR schemes (such as distribution-class power electronics-based static compensators) that work in coordination with smart inverters are required. There is an increasing need for advanced sensors with higher resolution and GPS-based time-synchronization capabilities to accurately capture distribution system dynamics. The data provided by these devices may also help detect fault currents at a remote location or high impedance conditions not sufficient to trip the normal protection. Implementation of synchrophasor technology in distribution systems and applications based on such may be desirable as a means to address operational and power quality issues derived from DER variability. 
As the renewable energy has come of age, the integration of renewable energy, especially wind and solar energy, reduces $\mathrm{CO}_{2}$ gas emission and its impact on the environment. With the availability of energy balancing supported by storage technology and autonomous control, the concept of a structured microgrid was defined [17]. In general, microgrids serve two roles:

- It is a mechanism that enables resources, customer, and network to be islanded from the main power grid so as to allow continuity of service on some basis during contingencies with energy provided by local resources,

- In both islanded and grid connected operations, it can serve as a scheduling/dispatch /control entity responsible for balancing load and generation, and in grid connected operations possibly serving as a point of aggregation up to higher level operations and even to wholesale markets.

\section{Challenges and Opportunities}

As discussed above, grid faces real challenges but offers opportunities to address environmental concerns and improve efficiency and reliability of electrical power supply. Specific challenges can be divided into three categories: technology and integration, processes and standards, and regulation and business models.

For the technical aspects, we need to: 1) Provide more functionality and performance to break the cost barrier; 2) Obtain higher reliability and efficiency to complement traditional "dumb" hardware; 3) Promote the adiabatic technology [18] as a regular performance requirement; 4) Develop better dielectric materials and packaging for smaller size and foot print; 5) Reduce the cost to drive acceptance for wide applications; and 6) Make the performance to be location and load insensitive. In other words to obtain efficiency, cost and size goals simultaneously.

For policy and standards aspects, we need to: 1) Develop practical standards for better interoperability of various different types of devices and systems; 2) Drive regulatory requirements for pricing and for tariff to address resilience and environmental concerns through adaptation of renewables and related new electronics hardware and software technologies; and 3) Stipulate policies that support adaptation of new solutions for local and global economic, reliability, and safety benefits.

To illustrate the points, we can zero in on a case in point with further discussion - the large power transformers. The large distribution transformers are ubiquitous and cost $\$ 1,000$ to $\$ 55,000$ to procure. They are typically $10-60 \%$ loaded with increased total ownership cost for the consumer. For an electronic power transformer (EPT), the benefits are more compact, more efficient at light load with reduced ownership cost for the consumer and more functionality, especially with new and more capable $\mathrm{SiC}$ or $\mathrm{GaN}$ power devices coming on line every month.

But the electronic transformer still facing challenges in cost. Refer to Fig. 3. To the left is a comparison table elec- tronics transformer relative to a traditional large power transformer [19]-[24]. According to the authors, the electronics transformer is still about 5 times more expensive than traditional designs. In order to reach its potential it needs to reach the target price of $\$ 10-\$ 40 / \mathrm{kVA}$. Another challenge is the losses are still 5 times larger than transitional transformers.

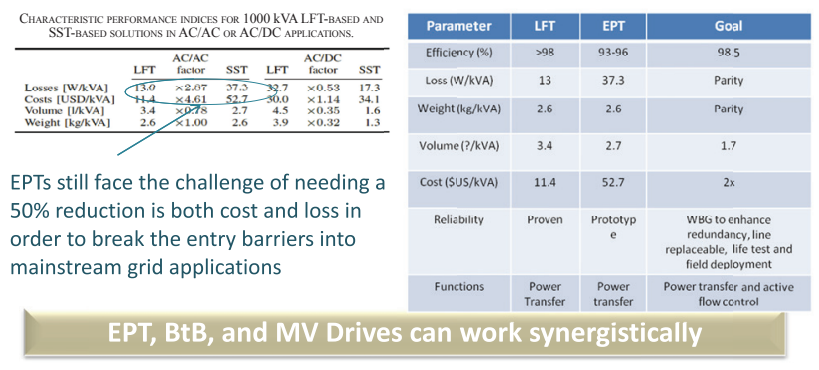

Fig. 3. Comparison of electronic transformer needs to consider its additional functionalities that any traditional power transformer cannot provide as shown in the table to the right.

Note that any comparison should include the additional functionalities that any traditional design simply cannot provide such as active control, fast response, flexibility, as it is illustrated in the right table of Fig. 3. EPTs, back-to-back converters and medium-voltage converters can work together synergistically to leverage the economy of scales, for both components production and hardware manufacturing, to bring the cost down to the desired level (a reduction of 3 to 5 times).

Electronic power transformer will continue to develop for more flexible electronic power transmission and distribution with more functionality such as those for transformer, for energy router, for electronic tab changers, and static VAR compensators.

Other opportunities for power electronic engineers are: 1) Invariant structure for fractal nature of the grid (radial or meshed); 2) Adiabatic, grid-scale, multilevel, multi-phase and multi-time-scale high-power conversion technology; 3) Grid-scale structure microgrids; 4) Reliability and fault management techniques for grids and microgrids; 5) Dynamic control of grids and microgrids; and 6) Substation retrofit and automation [25]-[28].

\section{GRID Modernization}

To face the challenges presented by a rapidly aging grid, US DoE has recently initiated a multi-year program on grid modernization [13] (November, 2015). Some examples of those efforts are described in [26], [27]. Started from the smart grid initiative, the investment for grid modernization has reached $\$ 1.1$ trillion, mostly for reliability and replacement purposes. The amount of investment cannot come from a single source. It has to be from multi sources such as government agencies at different levels, grid owners and operators, as well as consumers. So the grid modernization's first challenge is to enable the modernization drive to be a winwin-win situation for all parties involved [26]. 
The following are areas where further evolution and modernization is envisioned and needed to enable the T\&D system of the future.

- Integrated, holistic T\&D planning and operations - As the variability of distribution system net load increases, better coordination and information transfer is required. The ISO can no longer rely on simple load forecast bus allocation factors to forecast bus net loads but must be able to forecast PV production, as one example. More importantly, the use of DER to provide aggregated energy supply to the T\&D system and ancillary services to the wholesale markets will be increasingly valuable.

- Visibility and control of DER is vital to the electrical system of the future - This will require more advanced monitoring on the distribution system (where sensors cost more to acquire and install) as opposed to simply obtaining it from the DER. If the utility of the future is to operate the distribution system in real-time to manage reliability and operational challenges derived from DER variability and load - and the system is to be engineered to allow for that management with associated savings - then visibility and controllability is a must. Hosting increased DER penetration levels and avoiding worstcase distribution investments absolutely requires a level of real-time DER visibility.

- Improving flexibility, reliability, and DER hosting via advanced distribution system technologies It is necessary to leverage and modernize the existing infrastructure with electronic storage-supported distributed generation and active/dynamic control. The ideal scenario of the distribution system of the future of being able to monitor and control in real-time all key components of distribution circuits, is difficult to achieve in the short-term, given the monumental size and complexity of the distribution grid, and the large investments and required infrastructure (including communications systems) associated to this activity. However, a gradual transition toward this vision is possible and necessary to be able to provide a reliable, resilient, safe and secure service and operate the complex and highly dynamic distribution grid associated to high penetration of DER scenarios.

- Work force development - Well-trained workforce, capable of dealing with grid changes, is needed for the Grid of the Future.

In summary, building this intelligent grid is a monumental task (particularly on the distribution and grid-edge sides, which are vast and heterogeneous) that has led to the emergence of new concepts, technologies, and paradigms. Examples of this include debates regarding future grid architecture (a distributed, hybrid, or centralized grid); advances in grid modeling, simulation, and analysis; the introduction of the microgrid concept as an alternative to enhance resiliency and facilitate DER integration; and the convergence of information and operations technologies (IT/OT). As the power availability (frequently causally referred to as "grid reliability") is already $99.99 \%$, it is important to note that the transition phase to potentially fully distributed systems will be long. During the transition phase, a hybrid grid will be in existence for long time to come.

The pace of the transition toward a modernized grid, particularly on the distribution side, is a function of the existing and expected system conditions and trends of every utility system and market. For instance, utilities operating in states such as California and Hawaii, where DER proliferation is already a reality and where aggressive DER adoption will continue to achieve Renewable Portfolio Standard (RPS) goals, must continue this evolution toward a modernized distribution grid at a faster pace than utilities operating in emerging DER markets. Otherwise, DER proliferation will lead not only to significant operations, planning and engineering challenges and inefficiencies, but also will prevent utilities (and ultimately customers and society in general) to attain the potential benefits derived from the adoption of these technologies. Furthermore, since even larger-scale adoption of DER is inevitable, given the imminent (or existing) achievement of grid parity by PV-DG in these markets, additions in grid modernization infrastructures and systems should largely be considered "required" rather than "optional" investments to enable the normal operation of modern and future distribution systems. It is worth noting that utilities operating in states with incipient penetration levels of DER, recognize the imminence and urgency of preparing for the transition to this new paradigm, and are actively working on modernizing their distribution grids and overall practices so that they are suitable for operation in this new reality.

We are at a crossroads of making business and technical decisions that will allow us to optimally and cost-effectively manage the electrical power delivery. As business models and technology are changing, traditional grids and distributed grids/microgrids should be purposefully integrated as hybrid grids to fulfill all the consumer needs (e.g. resilience and cost-efficiency), with transmission as an enabler to support integration of all available renewable resources [15]. In order for us to have clear goals for the modernization efforts, basic characteristics of a modern grid need to be understood first. The six (6) basic characteristics of a modern grid were first identified in [28]. They are: 1) Electronic, 2) Fractal, 3) Structured with microgrids, 4) Fault tolerant and fault isolating, 5) resilient, and 6) Asynchronous (Detailed discussion is the future subject for) These characteristics look simple on paper, but represent significant challenges (opportunities) for the power electronics and electric power systems communities.

\section{PEAS Technology}

PEAS technology is experiencing profound changes. The top 10 trends in power electronics were presented in detail in [17]. Specifically, the top six (6) system-related trends are: 1) Renewables integration; 2) Structured microgrids (either dc-dominant or ac-dominant); 3) All things grid connected, 4) Transportation electrification; 5) Smart distributed systems (Smart grid, smart buildings, smart cities, etc.); and 6) 
Energy harvesting. And the top four (4) technological trends are: 1) Power conversion goes adiabatic (Virtually no heat), 2) Low-power conversion goes monolithic, 3) High-power conversion goes multilevel, and 4) Wide-band-gap devices are going main stream.

Among all the emerging areas, the system applications and related issues are most prominent. It also represents a large departure from traditional power electronics technical scope. Traditionally, power electronics is simply defines as power conversion technologies (converters) with solid-state power devices. While this served the purpose of establishing power electronics as a technical discipline within electrical engineering, it is not adequate for today's endeavors of power electronics engineers. Among all the new systems applications as outlined in [17], the grid modernization represents most challenges and hence it represents many opportunities.

Fig. 4 illustrates basic constituent technical thrust for grid modernization. A modern grid has nine (9) major areas. They are: 1) Microgrids; 2) Physical grid, interconnects, and power flow control; 3) All things grid connected (ATGC); 4) Command, control, compatibility, interoperability, standards and codes; 5) Sensor network, command, and telemetry; 6) Communication network and security; 7) System integration and resiliency; 8) System analytics and big data; and 9) Policy, economics, and market. The dark green areas represent the technical areas where the PEAS is directly involved. It is clearly seen that six out of nine areas are involved with PEAS. PEAS technology is playing an increasingly important role in the drive for grid modernization. Among all the desired characteristics for a modern grid, the electronictization is the very first step, since it lays the foundation for the modern and electronic grid.

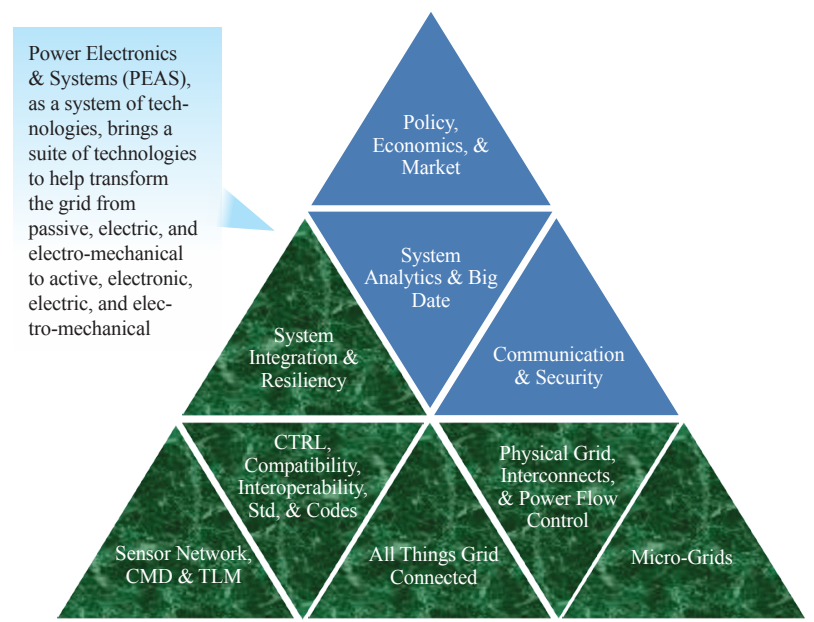

Fig. 4. PEAS technology occupies six (6) out of nine (9) main technical thrust areas for grid modernization.

\section{Grid Transformation to MeEt the Grand Challenge}

Looking at the top level of grid modernization, we can summarize the task of modernization simply as: to transform
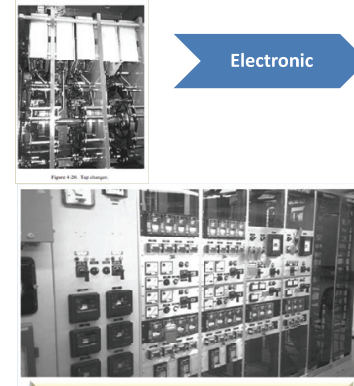

2E: Electric and Electromechanical

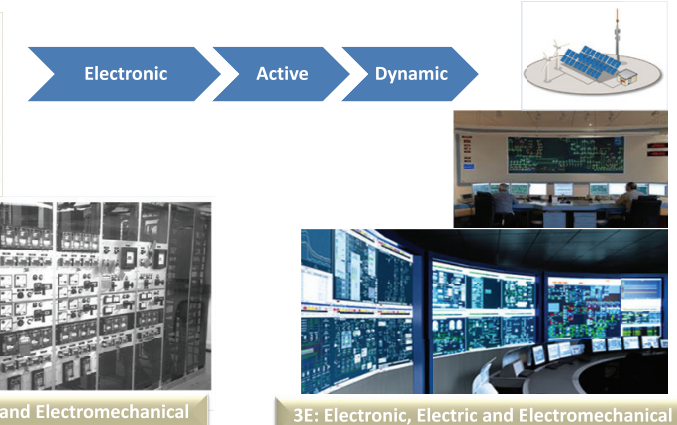

3E: Electronic, Electric and Electromechanical
Fig. 5. Grid modernization is largely a task to transform the grid from currently (by and large) electrical and electromechanical (EE) to electronic, electrical and electromechanical (EEE).

the power grid from current (by and large) passive/static control to active/dynamic control. Fig. 5 illustrates the concept in a pictorial fashion, where a wireless communication symbol is used to indicate layers of communication infrastructure for grid data. (Aspects of communication network are not pursued in this paper because of space limit.)

A vast amount of work related to the grid modernization is to lay the electronic foundation, upon which the active control (and then smartness) can be inserted. Since the computer related smart technologies are relative mature, the real challenges then lie with their deployment, including measurement, protection and control devices.

Relative to grid applications, the challenges can be categorized into six (6) major equipment and apparatus areas known as "all things grid connected (ATGC)," as first introduced in [17] and discussed in detail in [17], [18]. Fig. 6 presents a pictorial summary of all the six (6) categories and typical hardware types under each category. (Because of the limited space, detailed discussion is not presented in this article, except the main challenges. Interested readers are referred to [18] and its listed references.)

The main challenges in ATGC are: 1) Limited availability of solid-state devices for high voltage and high current applications; 2) Limited availability of high voltage dielectric materials and packaging techniques that can take extremely high voltage and high dv/dt values; and 3) Limited availability of high-efficiency, high reliability, low-power, and small

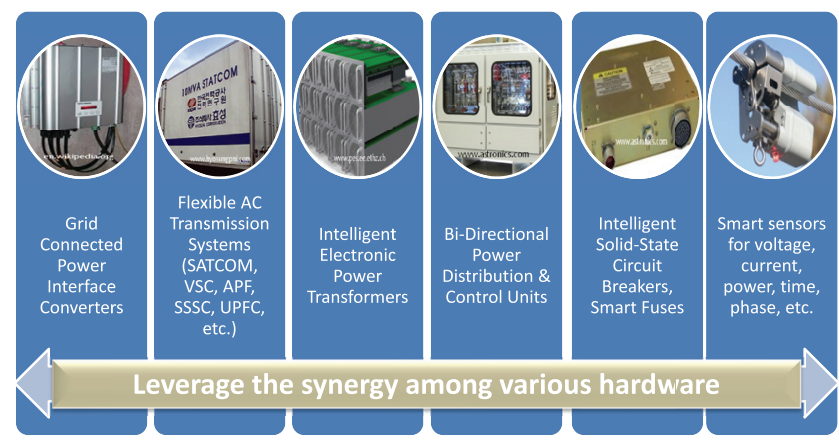

Fig. 6. Electronictization lays a foundation for grid modernization - four (4) out of six (6) 6 main thrust areas are synergistic. 
sized voltage, current, voltage and power sensors and limiters.

Furthermore, the retirement of conventional generation and reliance on more DG without appropriate back-up will also threaten the system's restoration/black-start capability. Many new generators do not include this capability due to complexity and cost. Renewable DG can inherently have this capability with the transition to grid-forming voltage source inverters and the addition of energy storage, however, creating opportunity for distributed, resilient, low cost blackstart capability. The development of monitoring and control schemes to enable this is needed, including further applications of distribution GPS-based synchronized measurements and advanced substation and distribution automation.

Let's discuss how we can meet the Grand Challenge. Refer to Fig. 7, where a typical daily grid loading scenario is presented together with the typical terms associated with defining a grid capacity [29]. It is clear that a grid capacity is typically sized to meet the peak power demand during a year. But the peak power demand usually happens only about a few days out of a year, or about $1 \%$. During the vast majority of the year the grid is underutilized and hence inefficient. A sensible way of achieving a better utilization is to devise a power flow and control scheme to leverage fully a grid's full installed capability.

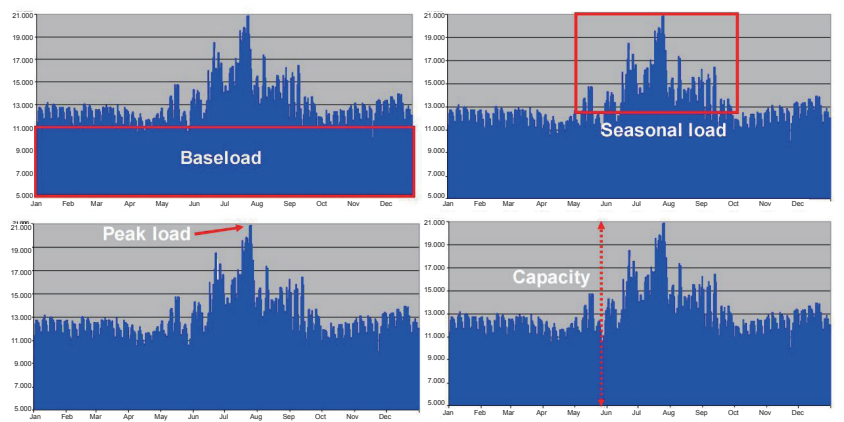

Grid capacity is over sized and largely underutilized

Fig. 7. Typical load conditions for a power grid and definition of frequently used terms for grid capacity.

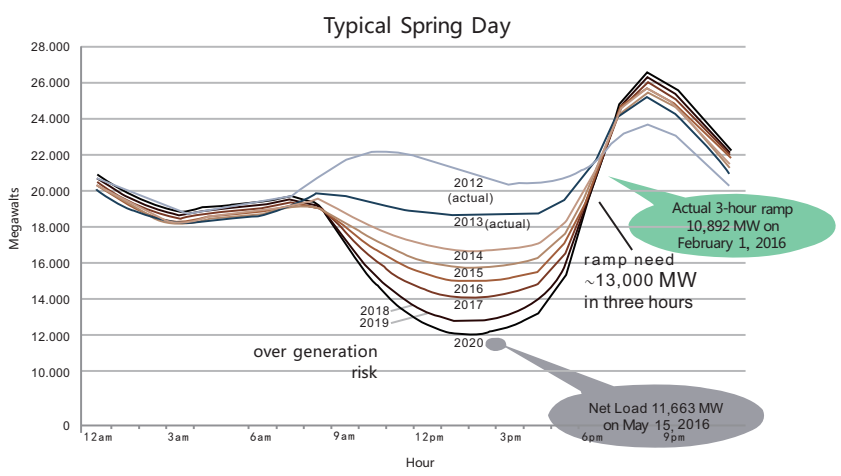

Fig. 8. 2016 update on the duck curve by California ISO (CASIO).
With the ever-increasing integration of solar power into the grid, the power demand seen by utilities typically resembles that of duck body profile during the day and hence the nickname "the duck curve" by CAISO. The 2016 update by CASIO is available in [30], as illustrated in Fig. 8. The duck curve shows steep ramping needs for utilities when sun does not shine and potential overproduction risk during the day when the sun shines in California. The fast ramping needs and the overproduction risk could both be handled effectively with PEAS technology together with sufficient storage capacity. PEAS-based equipment can be fast brought on line to provide the power needed during the day to meet peak demand, provided sufficient storage capacity is present.

The well-known peak shaving techniques [31] can then be used to store the over-produced solar power during the day and then release to power the peak demand during the evening (See [17], for a detailed discussion). If we assume that the peak power is typically $100 \%$ above the average load and that the amount of energy can be stored during the day is equal approximately to the additional power demanded by the load during the peak hours of the evening, then the real power can be "shaved" off to fill the valley of the duck curve. And then the load demand curve becomes effective a flat line, rather than a duck shaped. The flatness of the load profile has significant implication: It means that we can power twice as many customers (100\% growth) without having to increase the capacity.

In summary, energy storage (empowered by power electronics technology) promises the ability to mitigate renewable DER variability and improve T\&D utilization and economics. Technical, regulatory and economic barriers still impede its adoption even in states with aggressive programs for deployment. As storage is still fairly expensive, it is widely understood that "shared applications" - meaning multiple use of the same energy storage device, is a key to realizing the best economic potential from the technology. However, regulatory barriers and legacy paradigms are major obstacles to the rapid adoption of these technologies and their most effective uses. Energy storage is forced to fit into one of the generation, transmission, distribution or customer "buckets" and follow rules established for that asset class. Energy storage is in many viewpoints a new asset class of its own.

Furthermore, electric transportation holds significant promise for reducing dependence on oil and carbon footprint. Electrical systems can help improve the livability, workability and sustainability of "Smart Cities". Specifically addressing $\mathrm{EVs}$, the first purchase of an EV is likely to inspire more in the same neighborhood, which can lead to the emergence of "clusters" and the overload of system components. Distribution system capacity upgrades in combination with solutions based on DER and intelligent load control using power electronics could address these issues [32].

That is, we can meet the grand energy challenge without having to increasing the environmental footprint of carbonbased energy generation and reliance on fossil fuel. The discriminator is PEAS and energy storage technology and system 
engineering to integrate them together with any given local environmental predictions for sunshine and weather forecast and accompanying advanced distribution energy management systems [33], [34].

\section{Conclusions}

The following are overarching recommendations to achieve reliable, resilient and cost-effective delivery of electrical energy while supporting environmental targets for years to come:

- There is a need for grid modernization, with the speed of modernization adjusted to the pace of integration of clean DER and environmental and other regulatory targets.

- The architecture and design of the grid will have to be updated to accommodate very high penetration of DER and customer driven operations and planning.

- Enabling the transition to a modern grid requires changes in business models and regulatory policies, as well identification of the technical needs and development of new technologies.

- Continuous focus on improving reliability, resilience, safety, cost-efficiency, and customer flexibility to choose.

The six (6) basic characteristics of a modern grid are: 1) Electronic, 2) Fractal, 3) Structured with microgrids, 4) Fault tolerant and fault isolating, 5) Resilient, and 6) Asynchronous. Furthermore, the electronic power transformer will continue to develop for more flexible electronic power transmission and distribution with more functionality such as those for transformer, for energy router, for electronic tab changers, and static VAR compensators.

Other opportunities for power electronic engineers are: 1) Invariant structure for fractal nature of the grid (radial or meshed); 2) Adiabatic, grid-scale, multilevel, multi-phase and multi-time-scale high-power conversion technology; 3) Grid-scale structure microgrids; 4) Reliability and fault management techniques; 5) Dynamic control; and 6) Substation retrofit and automation.

\section{REFERENCES}

[1] Wm. A. Wulf, "Greatest achievements and grant challenges," in the Bridge, US Natina Academy of Engineering, vol. 30, nos. 3 \& 4, pp. 5-10, 2000 .

[2] C. Miller, et al.( 2014, Apr.). Achievig a resilient and agile grid. NRECA White Paper. [Online]. Available: http://www.nreca.coop/ wp-content/uploads/2014/05/Achieving_a_Resilient_and_Agile_ Grid.pdf

[3] D. Tan, "Trasnportation electrification, smart distributed systems, and beyond," the Inaugual IEEE Workshop on Wireless Charging (WoW), May, 2014. (Opening keynote)

[4] "World energy assessment," in United Nations Development Program, 2000.

[5] World population projected to reach 9.7 billion by 2050. United Nations Department of Economic and Social Affairs. [Online]. Available: http://www.un.org/en/development/desa/news/population/2015-report.html

[6] P. R. Ehrlich, and J. P. Holdren, "Impact of population growth," in Science, vol. 171, no. 3977, Mar., 1971.
[7] International Energy Agency, "Renewable energy coming of age," The Journal of International Energy Agency, Issue 2, Spring, 2012.

[8] R. A. Manning, "Renewable energy's coming of age: a disruptive technology?" in The Atlantic Council Issue Brief, Dec. 2015.

[9] M. Smith, and D. Ton, "Key connections: The U.S. Department of Energy's microgrid initiative," IEEE Power and Energy Magazine, vol. 11, no. 4, pp. 22-27, 2013

[10] NREL. (2010). Distributed solar PV eletricity system for resiliency. [Online]. Available: http://www.nrel.gov/docs/fy15osti/62631.pdf

[11] W. Cox, T. Considine, "Grid fault recovery and resilience: Applying structured energy and microgrids", in Innovative Smart Grid Technologies Conference (ISGT), 2014 IEEE PES, pp. 1-5, 2014.

[12] Patricia A. Hoffman, "2014 smart grid system report to the Congress," Office of Electricity Delivery and Energy Reliability, US Department of Energy, Aug. 2014.

[13] "Grid modernization multiyear program plan," US Department of Energy, Nov. 2015.

[14] B. C. Lesieutre, and J. H. Eto, "Electricity transmission congestion cost: a review of recent report," in Lawrence Berkerly Lab Report, LBNL-54049, 2003.

[15] IEEE QER Report to DOE. [Online]. Available: http://www.ieeepes.org/qer, September 2015

[16] D. Novosel, "Experiences with deployment of smart grid projects," Innovative Smart Grid Technology (ISGT) North America, Washington DC, Jan. 2012.

[17] D. Tan, "Emerging system applications and technological trends in power electronics," IEEE Power Electronics Magazine, pp. 38-47, Jun. 2015.

[18] D. Tan, "Power conversion is going adiabatic," IEEE Power Electronics Magazine, pp. 47-53, Dec. 2015.

[19] W. McMurray, "The thyristor electronic transformer: A power converter using a high-frequency link," IEEE Transactions on Industry and General Applications, vol. IGA-7, no. 4, pp. 451-457, Jul. 1971

[20] M. Kang, P. N. Enjeti, and I. J. Pitel, "Analysis and design of electronic transformers for electric power distribution system," in Industry Applications Conference, 1997. Thirty-Second IAS Annual Meeting, IAS '97., Conference Record of the 1997 IEEE, New Orleans, LA, vol.2, pp. 1689-1694, 1997.

[21] H. Wrede, V. Staudt and A. Steimel, "Design of an electronic power transformer," in IEEE 2002 28th Annual Conference of the Industrial Electronics Society (IECON 02), vol. 2, pp. 1380-1385, 2002.

[22] Xu She, and A. Huang, "Solid state transformer in the future smart electrical system," in Power and Energy Society General Meeting (PES), 2013 IEEE, Vancouver, BC, pp. 1-5, 2013.

[23] A. K. Sahoo, and N. Mohan, "A power electronic transformer with sinusoidal voltages and currents using modular multilevel converter," in Power Electronics Conference (IPEC-Hiroshima 2014 - ECCE-ASIA), 2014 International, Hiroshima, pp. 3750-3757, 2014.

[24] J. W. Kolar, and Ortiz, "Solid-state-transformers: key components of future traction and smart grid systems," in International Power Electronics Conference-ECCE Asia (IPEC 2014), Hiroshima, Japan, 2014.

[25] D. Tan, "Energy challenge and grid modernization," a Presentation to ARPA-E, Apr. 2016

[26] D. Tan, "Electronictization: a foundation for grid modernization," Invited Talk, University of California Riverside, ECE Department, Jan. 2015 .

[27] D. Tan, "Electronictization: a foundation for grid modernization," Chinese Journal of Electrical Engineering, the Inaugural Issue, pp. 1- 8, Dec. 2015. (Invited)

[28] D. Tan, "Six (6) basic charateristics of a modern grid," IPEMC-ECCE Asia, May 2016. (Keynote)

[29] P. Shoemaker, "Basic phtovatiaic (PV) systems for grid-tied applications," PG\&E Company, 2012.

[30] CAISO Fact Sheet, "What the duck curve tells us about managing a green grid," in California Independnet System Operator (CAISO), 2016.

[31] R. H. Stevenson, "Computerized peak shaving system for alleviating electric utility peak loads," US Patent \#04,023,043, May 1977.

[32] D. Novosel. (2016, Jul.). Paving the way for grid modernization. 
IEEE General Meeting, Boston. [Online]. Available: http://sites.ieee. org/pes-enews/2016/11/10/boston-proud-2016-ieee-pes-generalmeeting/ (Opening Speech)

[33] J.R Aguero, E. Takayesu, D. Novosel, and R. Masiello, "Modernizing the grid," IEEE Power and Energy Magazine, May/Jun. 2017. (to be published)

[34] D. Tan, and D. Novosel, "Towards a (more) electronic transmission and distribution (eT\&D)," CES Transactions on Electric Machines and Systems (TEMS), vol. 1 no. 1, Mar. 2017. (Invited inaugural paper)

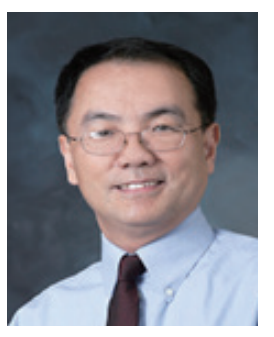

Don Tan received the Ph.D. degree from the California Institute of Technology, Pasadena, CA, USA.

$\mathrm{He}$ is a Distinguished Engineer and Senior Staff Manager with Northrop Grumman Aerospace Systems (NGAS), Redondo Beach, CA, USA. His double forward technology was licensed to a major telecom company. His adiabatic point-of-load technology has demonstrated a record efficiency of $99 \%$ at $10 \mathrm{~W}$. His APOL program has attracted tens of millions in customer investment. He is widely recognized as an authority in power management technology not only within NGC, with the National Aeronautics and Space Administration (NASA), the Air Force, and the government customer communities, contributing directly to our nation's top space programs.

Dr. Tan was a recipient of the NGAS Fellow Award in 2011, the Chinese Institute of Engineers, U.S., Asian American Engineer of the Year Award in 2010, the NGAS Asian American Achievement Award in 2009, the American Institute of Aerospace and Aeronautics Space Systems Award in 2008, the Joint Army Navy NASA Air Force Outstanding Achievement in Spacecraft Propulsion in 2007, the Northrop Grumman Space Technology President Award for Innovation, and the NGST Distinguished Patent Award both in 2002. He was President of the IEEE Power Electronics Society (PELS) from 2013 to 2014 and is inaugural Editor-in-Chief for the IEEE Journal of Emerging and Selected Topics in Power Electronics. He served as a Guest Editor-in-Chief for the IEEE Transactions on Power Electronics and the IEEE Transactions on Industry Applications. He serves on steering committees of numerous core power electronics conferences, including the
IEEE Energy Conversion Congress and Exposition (ECCE), ECCE Global Series, Applied Power Electronics Conference (APEC), and International Telecommunication Energy Conference. He served as PELS VP for Operations from 2009 to 2012 and VP for Meetings from 2001 to 2004, TPEL Associate Editor with Prof. Hoft from 1996 to 2001, entire APEC leadership positions from 1997 to 2000, the Chair of the Department of Defense/ IEEE Joint Working Group on Open Systems from 1997 to 2004, developing American National Standards Institute/IEEE Standards 1515-2000 and 1573-2003 (which are both used by the Environmental Protection Agency's Energy Star Program), and Chair of the PELS Los Angeles Council Chapter from 1995 to 2001. He served numerous times as a Topic Chair, a Session Chair, and a Reviewer for numerous IEEE conferences and transactions and he was elected IEEE Fellow.

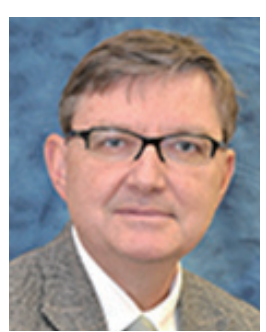

Damir Novosel received the M.Sc. degree in electrical engineering from the University of Zagreb, Zagreb, Croatia and the Ph.D. degree in electrica engineering from the Mississippi State University.

Currently, he is the President of Quanta Technology and Energized Services. He has over 29 years of experience working with electric utilities and vendors. He has developed and consulted on a number of products and methods to improve power system performance. He has created and managed several reputable and successful organizations that developed innovative technology and industry best practices in various areas of power systems. Prior to joining Quanta Technology, he was the President of T\&D Consulting at KEMA in the United States. He has also held various positions in ABB including Vice President of global development and product management for automation products. He currently holds 16 U.S. and international patents. He published over 100 articles in refereed journals and conference proceedings in various areas of power systems.

Dr. Novosel is currently President of the IEEE Power and Energy Society (PES) and member of the IEEE PES Governing Board. He is co-chairing Performance Requirement Task Team for the North American Synchro Phasor Initiative (NASPI), large-scale activity of the North American utilities on implementation of Synchronized Phasor Measurements. His work in electrical power system monitoring, protection, control, and automation earned him international recognition and he was elected IEEE Fellow. 